\title{
A Comparative Study between LGBTIQ+ and Heterosexual Population in Adult Close Friendship: Meaning in Life, Spiritual Similarity, Emotional Forgiveness and Post Transgression Growth
}

\author{
Eshita Mandal ${ }^{1}$, Aishwarya Shinde ${ }^{2}$ \\ 1,2Department of Applied Psychology, University of Mumbai \\ Corresponding author: Aishwarya Shinde \\ Email - shindeaishwarya2017@outlook.com
}

\begin{abstract}
Background: The study addressed the Relational Spirituality model in a way that it retained the interpersonal objective appraisal i.e., perception of Spiritual Similarity, and added Meaning in Life to know its unique contribution and replacement in place of Spiritual appraisals about the victim, transgressor and the transgression with Sacred. Minority Stress Theory highlighted the relevance of testing the model on both of these populations separately.

Methodology: 40 participants of each population participated in the study. The research design was correlational in nature, as no variable or condition was manipulated by the experiment or otherwise. To find the difference between two groups (Heterosexual and LGBTIQ+ populations) in terms of variables under study, independent populations $t$ test was used for analysis and to assess the impact of independent variables, multiple regression analyses were conducted on the data.

Results: Search of Meaning and Spiritual Similarity significantly influenced prevalence of negative affect on interpersonal hurtful event in LGBTIQ+ community. In heterosexual population, Presence of Meaning and Spiritual Similarity influenced the Emotional Forgiveness. No significant difference was found in both the populations with respect to the variables in study.

Conclusion: Search of Meaning was influential for LGBTIQ+ and Presence of Meaning for heterosexual population with the common significant predictor of Spiritual Similarity.
\end{abstract}

Keywords: forgiveness, meaning in life, LGBTIQ+, presence, search, interpersonal transgression.

$$
\text { (Paper received }-15^{\text {th }} \text { November 2019, Peer review completed }-20^{\text {th }} \text { December 2019) }
$$

(Accepted $-26^{\text {th }}$ December 2019)

\section{INTRODUCTION}

LGBTIQ+ community faces unique life stressors- the first being struggling with acceptance of identity which is more likely to expose them to the question of the meaning of their life. Current research suggests their identity status in society predisposes them toward developing crisis competency, i.e. the strength and open attitude to deal with adverse life situations, tendency to learn from people and appreciate differences [1]. In consideration of their sexual orientation and all the negative mental health outcomes associated with selfunacceptance, it is imperative that the frequency, the nature of interpersonal transgression, and the way they cope with it will differ in comparison to their heterosexual counterparts. If any person experiences the average number of transgressions in friendships, the risk of serious transgressions increases with the affiliation to the community, from their close friends who can be of any orientation and regarding any matter [2]. The interpersonal transgression in romantic relations is relatively explored area for the community. Friendship is the arena relatively untouched serving as a protective factor, because people from community 
are more likely to come out to their friends as compared to parents. Thus, it is important to address the adverse consequence of sudden loss of such a social support by major hurtful interaction. Equally important and complementary would be to explore it, in combination with mechanism which is deemed as an adaptive coping mechanism in the psychological literature- Spirituality or Spiritual Cognitions. According to Relational Spirituality and Spiritual Transformation Model [3], post any interpersonal transgression (hurtful event), the intention to forgive can be traced to cognitive appraisals of the relationship of each of transgressor, victim, and transgression to the Sacred. Meaning in Life is cognitive and motivational construct which overlaps with the spiritual appraisals about the relation of the victim, transgressor and the transgression, each of them with the Sacred [4]. Spiritual appraisals and Meaning in Life both relate to how the individual sees the world in relation to something beyond themselves. In the age group of 17-35 years, the heterosexual population obtains the constancy of Meaning in Life, LGBTIQ+ community might undergo maladaptive identity development and may get too invested and centred around their identity to define the other areas of life. This may lead to altered Meaning in Life. Also, it has been reported that when considering the decision to forgive after interpersonal transgression, similarity with offender (person who hurts) is important factor [5]. In this model, Spiritual Similarity is the perceived similarity of the worldviews which helps to explain the forgiveness. Research evidences have been inconclusive in terms of this community's tendency to forgive. According to a study [6], one source of meaning in people's life is others. When negative event in the form of offense is inflicted, the sense is disrupted. To maintain that, people use forgiveness, which helps people find additional meaning and it is an adaptive response to interpersonal transgression when one expects to continue the relationship. Post-traumatic growth is one of the consequences stemming out of positive construct of Spirituality. The crisis competency that the community develops as a result of series of transgression centring their identity can mimic the cognitive growth which is conceptualized as posttraumatic growth.

This paper aims to study the impact of Meaning in Life perceived and Spiritual Similarity felt for the close friend at the time of any serious interpersonal hurtful event inflicted by the close friend on the Emotional Forgiveness and Post-Transgression Growth, in community population and the heterosexual population. The past studies utilized the decision to forgive as the outcome variable. But in the current study, the Emotional Forgiveness is the outcome variable because to assess the impact of cognitive appraisals of Meaning in Life, the immediate outcome variable that will get affected is emotion as it directly springs from cognition. Thus, it was hypothesized that Meaning in Life and Spiritual Similarity would predict Emotional Forgiveness. Meaning in Life has two elements and past studies have demonstrated differential results of both of them: Presence of Meaning leading to positive consequences, stable sense of worldview and less frustration; whereas Search of Meaning creates the confusion and frustration in the face of established way of perception [7]. Thus, it was hypothesized that Search of Meaning and Spiritual Similarity will have significant negative influence on Reduction in Negative Affect only. It is a sub scale of Emotional Forgiveness Scale. It would mean that Search of Meaning and Spiritual Similarity will lead to unforgiveness which will be reflected as low scores on Reduction in Negative Affect sub scale. Presence of Meaning presupposes the pre-existing meaning to perceive the life. This meaning is broken by the hurtful event in interpersonal relationship [8]. According to Van Tongeren forgiveness works as a meaning restoration mechanism. If hurtful event in friendship disrupts the already established meaning, then forgiveness restores it and provides additional relief and explanation of trust as the person is also perceived as someone who is spiritually similar. Thus, it was hypothesized that Presence of Meaning and Spiritual Similarity will significantly predict Emotional Forgiveness. Once the restoration of meaning is done, the individual may modify the schema or frame of meaning in order to adjust the recently experienced major stressful event. Thus, it was hypothesized that Presence of Meaning and Spiritual Similarity will significantly predict Post Transgression Growth. Past studies [9] found no significant difference in two populations for Existential, Spiritual and Religious Well-being. But there seems to be inconclusive findings regarding whether the variables Meaning in Life (as stated above), Spiritual Similarity, Emotional Forgiveness and PostTransgression Growth vary significantly as per populations. 


\section{METHODOLOGY}

\section{Participants}

Two populations $(\mathrm{N}=80)$ were used in this study, 40 heterosexuals and 40 individuals identifying themselves as LGBTIQ+ community. To participate in the study, participants needed to meet two criteria: 1. They needed to describe severe hurtful event; 2. In case of LGBTIQ+, they need to identify themselves overtly or covertly with any of the LGBTIQ+ identities. The individuals belonging to age group 17 to 35 participated in the research. Majority of the population was dominated by Gay men accounting for $45 \%$, followed by $25 \%$ of Bisexual, $10 \%$ asexual, $5 \%$ transgender, and there was also the representative combination of minority gender, romantic and sexual orientation like panromantic, etc.

\section{Instruments}

For demographic details, participants indicated their age, sexual orientation, relationship status and they also described briefly the hurtful event, the intensity of hurt and the time passed since that event occurred.

1. Meaning in Life Questionnaire (MLQ): It is 10-items scale. It has 7-point likert scale ranging from 1 (Absolutely Untrue) to 7 (Absolutely True). The coefficient alphas of the scale range in the low to high 0.80 for the Presence subscale and mid 0.80s to low 0.90 for the Search. For presence, factor loadings range from 0.56 to 0.80 . For Search factor, they are from 0.63 to 0.76 . It is said to have a satisfactory criterion validity [10].

2. Similarity of the Offender's Spirituality Scale (SOS): It contains 9-items with 7-point likert scale from $0=$ completely disagree to $6=$ completely agree. Cronbach's alphas for Spiritual Similarity is 0.93, for human spirituality, it is 0.86 and for full scale, it is 0.91 . This hints at the sound internal consistency of the scale. Factor analytic evidence shows that Spiritual Similarity explains $50 \%$ of variance and human similarity explains $15 \%$ [11].

3. Emotional Forgiveness Scale (EFS): It contains 8 items with 5-point likert scale ranging from 1 (Strongly Disagree) and 5 (Strongly Agree). The test-retest reliabilities for full scale is 0.73 , for Prosocial intentions that is for Presence of positive affect is 0.72 and for inhibition of harmful intentions i.e., Absence of Negative Affect is 0.68. The scale has significant construct validity and discriminant validity [12].

4. Post-Traumatic Growth Inventory-Short Form (PTGI-SF): It has 10 items with 6-point scale ranging from 0 (I did not experience this change as a result of my crisis) to 5 (I experienced this change to a very great degree as a result of my crisis). The scale seeks to assess the changes in five areas: Relating to others items, New possibilities, Personal strength, Spiritual change, Appreciation of life. Internal reliability for factors ranged from 0.72 to 0.81 and 0.89 for Full scale. Correlation with full-form ranged from 0.72 to 0.89 for factors [13].

\section{Procedure}

The conceptualization of the study, measures to use in the study were chosen and were administered to participants via Google Form and in paper-and-pencil format. The validity of Google forms was inferred [14]. It was used due to convenience to gather large population in short time. The Participants were made aware about the study via other social media. The participants were introduced to the research and the purpose of the study. Following the ethical principles for psychological research parallel to World Medical Association's the Declaration of Helsinki Ethical Principles for research involving Human Subjects, they were informed about their rights as the participants which included Description of the research, Risks and Discomforts, Confidentiality, Voluntary Participation. This was followed by scales of the variables including description of hurtful event and reporting of its time interval and intensity. All the participants filled the form online. The participants were approached through NGOs, groups on social networking sites.

\section{RESULTS}

Preliminary analyses like mean, SDs and correlations were carried out for two separate populations. 
Table 1: Mean, SDs of all variables for both populations of LGBTIQ+ and heterosexuals

\begin{tabular}{|l|l|l|l|l|}
\hline \multirow{2}{*}{ Variables } & \multicolumn{2}{|l|}{ LGBTIQ+ Population } & \multicolumn{2}{l|}{ Heterosexual Population } \\
\cline { 2 - 5 } & Mean & SDs & Mean & SDs \\
\hline Presence of Meaning & 24.73 & 7.64 & 24.67 & 6.64 \\
\hline Search of Meaning & 24.38 & 8.04 & 26.13 & 6.38 \\
\hline Meaning in Life & 49.1 & 11.94 & 50.79 & 7.92 \\
\hline Spiritual Similarity & 27.85 & 9.07 & 28.85 & 9.67 \\
\hline Increase in Positive Affect & 14.07 & 4.37 & 13.10 & 4.78 \\
\hline Reduction in Negative Affect & 10.80 & 3.65 & 11.69 & 4.46 \\
\hline Emotional Forgiveness & 24.88 & 5.37 & 24.79 & 7.40 \\
\hline Post-transgression Growth & 27.48 & 13.91 & 28.31 & 11.87 \\
\hline
\end{tabular}

The $t$ test analysis was computed to compare the scores for all the variables of both the population: LGBTIQ+ and the Heterosexual individuals. The test results reflected that there were no significant differences between the two groups. Thus, it was supported that the difference in sexuality does not mean the difference in how they perceive the meaning of their life, how similar they find their friends in terms of their worldview, how they restore the meaning in their relationship and how they build the new sense of their life. Correlation was done to establish the relationship among the variables.

Table 2: Correlation between Presence of Meaning (PR), Search of Meaning (SE), Meaning in Life (MN), Spiritual Similarity (SS), Increase in Positive Affect (PA), Reduction in Negative Affect (NA) and Post Transgression growth (PTG) for LGBTIQ+ population.

\begin{tabular}{|l|l|l|l|l|l|l|l|l|}
\hline Var. & PR & SE & MN & SS & PA & NA & EF & PTG \\
\hline PR & 1 & .160 & $.747^{* *}$ & .256 & .160 & .085 & .189 & .158 \\
\hline SE & & 1 & $.776^{* *}$ & $.425^{* *}$ & .118 & $-.546^{* *}$ & $-.275^{*}$ & $.273^{*}$ \\
\hline MN & & & 1 & $.450^{* *}$ & .182 & $-.313^{*}$ & -.065 & $.285^{*}$ \\
\hline SS & & & & 1 & $.491^{* *}$ & -.242 & .234 & $.337^{*}$ \\
\hline PA & & & & & 1 & -.113 & $.737^{* *}$ & $.282^{*}$ \\
\hline NA & & & & & & 1 & $.588^{* *}$ & -.187 \\
\hline EF & & & & & & & 1 & .102 \\
\hline PTG & & & & & & & & 1 \\
\hline
\end{tabular}

Table 3: Correlation between Presence of Meaning (PR), Search of Meaning (SE), Meaning in Life (MN), Spiritual Similarity (SS), Increase in Positive Affect (PA), Reduction in Negative Affect (NA) and Post Transgression growth (PTG) for Heterosexual population.

\begin{tabular}{|l|l|l|l|l|l|l|l|l|}
\hline Variable & PR & SE & MN & SS & PA & NA & EF & PTG \\
\hline PR & 1 & -.260 & $.629^{* *}$ & .026 & .115 & $.330^{*}$ & $.273^{*}$ & -.105 \\
\hline SE & & 1 & $.587^{* *}$ & .216 & -.163 & -.180 & -.214 & .218 \\
\hline MN & & & 1 & .196 & -.036 & .132 & .056 & .088 \\
\hline SS & & & & 1 & $.451^{* *}$ & .123 & $.366^{*}$ & .138 \\
\hline PA & & & & & 1 & $.281^{*}$ & $.816^{* *}$ & .012 \\
\hline NA & & & & & & 1 & $.784^{* *}$ & -.033 \\
\hline EF & & & & & & & 1 & -.012 \\
\hline PTG & & & & & & & & 1 \\
\hline
\end{tabular}

**Correlation is significant at the 0.01 level (1-tailed).

* Correlation is significant at the 0.05 level (1-tailed). 
To investigate the effect of Meaning in Life and Spiritual Similarity on Emotional Forgiveness and post transgression growth in LGBTIQ+ and heterosexual population, multiple regression analyses were conducted. In order to predict the reduction in negative affect from Search of Meaning and Spiritual Similarity for LGBTIQ+ population, multiple regression analysis was carried out.

Table 4: Multiple regression with predictor variables: Search of Meaning (SE) and Spiritual Similarity (SS) and criterion variable: Reduction in Negative Affect (NA) for LGBTIQ+ population

Model Summary

\begin{tabular}{|c|c|c|c|c|c|c|}
\hline Predictors & Criterion & $R$ & $R S q$ & $R$ adj & $F$ & Sig. \\
\hline SE, SS & NA & .55 & .30 & .26 & 7.85 & .001 \\
\hline & Predictors & Criterion & B & $t$ & Sig. & \\
\hline & SE & \multirow[t]{2}{*}{ NA } & -.54 & -3.55 & .001 & \\
\hline & SS & & -.01 & -.08 & NS & \\
\hline
\end{tabular}

As shown in Table 4, the strength of the given model being $.30(\mathrm{R}$ squared $=0.30)$ and the correlation exists among the variables being $0.55(\mathrm{R}=0.55)$, the multiple regression analysis obtained $\mathrm{F}$ value for this model is 7.85 at 2 and $36 \mathrm{df}$, which has come to be significant at .001 level $(\mathrm{F}=7.85, \mathrm{df}=2,36, \mathrm{p}<0.01)$. That is, significant interaction has been found between two variables to explain $30 \%$ variance contributed by the model in the prediction of reduction in negative affect was significant $(\beta=-0.54)$ with $t$ value of -3.55 significant at 0.001 level $(t=-3.55, p<0.05)$. Thus, it can be said that interaction is predicted with greater precision. But the closer look at significance of other parameter estimators implies that search has significant causal factor $(\mathrm{p}=0.001)$ for reduction in negative affect accounting for beta coefficient -0.54 .

Table 5- Multiple regression with predictor variables: Presence of Meaning (PR) and Spiritual Similarity (SS) and criterion variable: Emotional Forgiveness (EF) for Heterosexual Population Model Summary

\begin{tabular}{|l|l|l|l|l|l|l|}
\hline Predictors & Criterion & $\boldsymbol{R}$ & $\boldsymbol{R} \boldsymbol{S} \boldsymbol{q}$ & $\boldsymbol{R}$ adj & $\boldsymbol{F}$ & Sig. \\
\hline PR, SS & EF & .45 & .20 & .16 & 4.597 & .05 \\
\hline
\end{tabular}

Coefficients

\begin{tabular}{|l|l|l|l|l|}
\hline Predictors & Criterion & $\boldsymbol{\beta}$ & $\boldsymbol{t}$ & Sig. \\
\hline PR & \multirow{2}{*}{ EF } & .29 & 1.77 & NS \\
\cline { 3 - 5 } SS & & .27 & 2.41 & .05 \\
\hline
\end{tabular}

In order to predict the Emotional Forgiveness from Presence of Meaning and Spiritual Similarity in heterosexual population, As shown in Table 5 the regression model predicting Emotional Forgiveness by regressing on Presence of Meaning and Spiritual Similarity obtained the correlation of $.45(R=0.45)$ with the strength of the regression model being $.20(R$ squared $=0.20)$ has obtained $F$ value 4.597 at 2 and $36 \mathrm{df}$ is significant $(F=4.597, \mathrm{df}=2,36, p<0.05)$. In total, the model contributes $20 \%$ of variance to predict the Emotional Forgiveness ( $\beta=0.49$ for Spiritual Similarity, $p<0.05$ ) Individually, Presence of Meaning does not account for significant prediction as shown by beta value $0.29(\beta=0.29, t=1.77, \mathrm{df}=38$, NS). But the Spiritual Similarity is significant in tracking changes in the emotional growth by 0.27 units $(\beta=0.27, t=$ $2.41, \mathrm{df}=38, p<0.05$ ). Thus, it can be understood that only Spiritual Similarity predicts the Emotional Forgiveness, and not the Presence of Meaning. The interaction between the predictors is also significant but they do not causally explain the Emotional Forgiveness. 


\section{DISCUSSION}

The Search of Meaning was associated with confusion and frustration. According to researchers, people with minority status is invested in search of their identity and its relevance. They react with bitterness to severe interpersonal transgression in friendship, especially when they perceive the close friend having greater Spiritual Similarity inflicting it. Thus, it was predicted that Search of Meaning and Spiritual Similarity both will inversely influence the forgiveness. The current study found the support for this prediction. In heterosexual population, Presence of Meaning and Spiritual Similarity had significant impact on Emotional Forgiveness which is in line with past researches which stated that Presence of Meaning is associated with lesser confusion, positive interpretation of events, adaptive coping mechanisms, the ability to interpret events in life in the context of applied meaning and similarity reduces the feelings of injustice and replaces with feelings of vulnerability, which are restored with the empathy-facilitated mechanism of forgiveness [14-16]. Meaning in Life and Spiritual Similarity did not create any impact on forgiveness and post transgression growth. Wong [15] explained that the interpretation of Meaning in Life can be done in three ways: Mission, Calling and Transcendence. The Transcendence can be predicted to correlate highly with spiritual cognitions and thereby Emotional Forgiveness. In addition to this, researchers [15] state that the Meaning in Life can be measured as a trait or a state. Thus, at any given time, the trait meaningfulness revoked to give adaptive reactions to hurtful event was difficult to decipher. In community, forgiveness was not predicted by the Meaning in Life and Spiritual Similarity. In the present study, forgiveness was understood in terms of lessening the negative affect and increase in positive affect. Participants might have forgiven the victims in terms of reducing their negative affect toward them but the positive affect might not have been prevailed. Thus, leading to insignificant finding. Also, research by Pearce [16] explicated the situational causes of unforgiveness. Out of five causes explained, two are most relevant in the context of present study. First, people do not forgive the offender because they want to maintain the lost self-esteem that vulnerabilities of hurt incur. Second, the reparational work by the transgressor matters in the post transgression period to convince to the victim that hurt was unintentional or that it was intentional in the spite of moment but later the transgressor feels sorry about it. Mostly the incidences reported hinted at the presence of poor reparative work by the transgressor. Thus, leading to unforgiveness in current population. Meaning in Life was significantly found to have correlation with post transgression growth. This is in line with the past research by Shenkman and others [1] which have stated that crisis competency makes this community open to experience, they learn to actively strive for meaning in their experience. The result of this is personal growth. The Meaning in Life, Spiritual Similarity, Emotional Forgiveness and post transgression growth did not vary as per the populations. In their respective populations, the importance of certain IVs in predictions are different (in LGBTIQ+, Search of Meaning stood out but in heterosexuals, Presence of Meaning was impactful).

Tripathi and Kacker [9] conducted the comparative study on Spiritual, Existential and Religious Well-being stated beautifully in their research paper the following conclusion: "There is no significant difference in...It is because the only difference in them is their sexual orientation and it is not an abnormality because of which they should differ in their spirituality and wellness. The life of homosexual and heterosexual are similar, just that orientation of homosexual towards their sexual partners is different, but that does not mean that their spiritual well-being will be different from heterosexuals. Though they face lots of problems in leading their life because of society's stereotypical thinking pattern, they find it hard to move in society with others not because they know they are odd or different in comparison to others, because of other people who think they are different from them".

Two findings were essential when considered across LGBTIQ+ and heterosexual populations: increase in positive affect, the subscale of Emotional Forgiveness, was comparatively higher for both the populations. This highlights the fact that despite difference in importance of different dimensions of meaning in i.e., presence and search, the individual tends to have relatively or regain positive affect toward the friend. Past research by Sun [17] stated that the relationship strengthening effect of hurtful events does occur only when the minor transgressions are happening. Despite majority of the participants belonging to different sexual orientations maintained or regained the positive affectivity toward the close friend. Another striking observation from the data is that Spiritual Similarity is important for both the populations. This could be 
because Spiritual Similarity gives the closer look at the situation who the victim perceives as sharing the same ideals and philosophy of life with.

To summarize, the hypothesis 'Reduction in Negative Affect' is predicted by Search of Meaning and Spiritual Similarity is supported by the multiple regression analysis for LGBTIQ+ community and the hypothesis Emotional Forgiveness is predicted by Presence of Meaning and Spiritual Similarity is supported for heterosexual population. Yet, multicollinearity seems to have affected the data due to which both the predictor variables does not stand out strongly influencing. The other hypotheses tested out by multiple regression analysis and $t$ test are not supported by the data in this study.

\section{CONCLUSION}

The finding that there is no difference between the two populations in terms of studied variables is very reassuring that the difference in one's sexual orientation does not imply difference in the person's psychological make-up. The important contribution of the study is that it mainly aims to explore the severe interpersonal transgression and it reflected the significance to study post transgression growth which was rarely considered in the area of hurt research.

People seek help from mental health professionals to learn skills to solve their own problems or to facilitate their personal growth, which makes them own the responsibility for their choices. From a therapist's perspective, the findings from such studies which aim to tap on basic mechanism which turns the adversity into an opportunity to grow, states and describes the protective factor are very crucial to understand the basic goal of the therapy, which element is to be added into the therapy based on the here-and-now of the therapeutic endeavours. Research directed at understanding the curative role of Meaning in Life is beneficial. The current study highlights that the role and approach of mental health professionals remains the same irrespective of one's sexual orientation.

\section{Limitations}

The researchers did not get the representation of non-English speaking population due to lack of opportunity to translate the scales in regional language used in study. Secondly though the population size was adequate to conduct the parametric statistical analyses but was not too good to consider the regression analysis [18]. The population size was restricted to 80 inclusive of both the populations. In this study, variables related to additional information about hurtful event like intensity of hurt, the mode of hurt (an act or a message), duration of the hurt, type of hurtful event reported, perceived intentionality of the hurt and cognitive proximal variables like attributions, ruminations, the relationship outcomes could have given additional insight into the pattern of results.

\section{REFERENCES}

1. Shenkman G, Ifrah K, Shmotkin D. Meaning in Life Among Middle-Aged and Older Gay and Heterosexual Fathers. J Fam Issues 2018;39(7):2155-73.

2. Paterson JL, Brown R, Walters MA. The short and longer term impacts of hate crimes experienced directly, indirectly, and through the media. Personal Soc Psychol Bull 2019;45(7):994-1010.

3. Sandage SJ, Shults FL. Relational Spirituality and Transformation: A Relational Integration Model. J Psychol Christianity 2007;26(3).

4. Davis DE, Worthington Jr EL, Hook JN, Hill PC. Research on religion/spirituality and forgiveness: A metaanalytic review. Psychol Religion Spiritual 2013;5(4):233-55.

5. Peets K, Hodges EV, Salmivalli C. Forgiveness and its determinants depending on the interpersonal context of hurt. J Exp Child Psychol 2013;114(1):131-45.

6. Van Tongeren DR, Green JD, Hook JN, Davis DE, Davis JL, Ramos M. Forgiveness increases meaning in life. Soc Psychol Personal Sci 2015;6(1):47-55.

7. Newman DB, Nezlek JB, Thrash TM. The dynamics of searching for meaning and presence of meaning in daily life. J Personality 2018;86(3):368-79.

8. Schultz JM, Tallman BA, Altmaier EM. Pathways to posttraumatic growth: The contributions of forgiveness and importance of religion and spirituality. Psychol Religion Spiritual 2010;2(2):104-10.

9. Tripathi R, Kacker P. Spiritual Well Being of Heterosexual and Homosexual: A Comparative Study. IOSR J Humanities Soc Sci (IOSR-JHSS) 2013;7(5):26-31.

10. Steger MF, Frazier P, Oishi S, Kaler M. The meaning in life questionnaire: Assessing the presence of and search for meaning in life. J Couns Psychol 2006;53(1):80-8. 
11. Davis DE, Worthington Jr EL, Hook JN, Van Tongeren DR, Green JD, Jennings II, David J. Relational spirituality and the development of the Similarity of the Offender's Spirituality Scale. Psychol Religion Spiritual 2009;1(4):249-55.

12. Williams J, vanOyen Witvliet C, Nir T, Dueck A. Decisional and Emotional Forgiveness: Conceptualization and Development of Self-Report Measures Everett L. Worthington, Jr., Joshua N. Hook, Shawn O. Utsey Virginia Commonwealth University.

13. Cann A, Calhoun LG, Tedeschi RG, Taku K, Vishnevsky T, Triplett KN, Danhauer SC. A short form of the Posttraumatic Growth Inventory. Anxiety Stress Coping 2010;23(2):127-37.

14. Leung DY, Kember D. Comparability of data gathered from evaluation questionnaires on paper and through the internet. Res High Educ 2005;46(5):571-91.

15. Wong PT. Self-transcendence: A paradoxical way to become your best. Int J Existent Posit Psychol 2016;6(1):9-16.

16. Pearce HS. The identification and measurement of barriers to forgiveness following an interpersonal transgression (Doctoral dissertation) University of Adelaide: Australia; 2007.

17. Sun MC. The positive side of hurtful communication: when hurt feelings improve close relationships (Doctoral dissertation). University of Texas; 2017.

18. Green SB. How many subjects does it take to do a regression analysis. Multivar Behav Res 1991;26(3):499510.

$* * * * * * * * * * * * * * * * * * * * * * * * * * * * * * * * * * * *$

Acknowledgements - We thank Department of Applied Psychology, University of Mumbai for the place accommodation of the meetings of this study. We also express heartfelt gratitude to various NGOs and social media sites which helped in data collection phase.

Conflict of Interest - Nil

Funding - Nil 